\title{
Description of Lysinibacillus sinduriensis sp. nov., and transfer of Bacillus massiliensis and Bacillus odysseyi to the genus Lysinibacillus as Lysinibacillus massiliensis comb. nov. and Lysinibacillus odysseyi comb. nov. with emended description of the genus Lysinibacillus
}

\author{
Min Young Jung, ${ }^{1}$ Joong-Su Kim, ${ }^{2}$ Woon Kee Paek, ${ }^{3}$ Igor Styrak, ${ }^{4,5}$ \\ In-Soon Park, ${ }^{1}$ Yeseul Sin, ${ }^{1}$ Jayoung Paek, ${ }^{1}$ Keun Ae Park, ${ }^{1}$ \\ Hongik Kim, ${ }^{6}$ Hong Lim Kim ${ }^{7}$ and Young-Hyo Chang ${ }^{1}$ \\ ${ }^{1}$ Korean Collection for Type Cultures, Biological Resource Center, KRIBB, 125 Gwahak-ro, \\ Yuseong-gu, Daejeon 305-806, Republic of Korea \\ ${ }^{2}$ Jeonbuk Branch Institute, Molecular Bioprocess Research Center, KRIBB, 181 Ipsin-gil, \\ Jeongeup-si, Jeollabuk-do 580-185, Republic of Korea \\ ${ }^{3}$ National Science Museum, 32-2 Guseong-dong, Yuseong-gu, Daejeon 305-705, \\ Republic of Korea \\ ${ }^{4}$ Department of Microbiology, Institute of Animal Physiology, Soltesovej 4-6, 04001 Kosice, \\ Slovakia \\ ${ }^{5}$ Department of Biotechnology, Institute of Geotechnics, Watsonova 45, 04353 Kosice, Slovakia \\ ${ }^{6}$ R\&D Division, Vitabio Inc., Yongjeon-dong 21-3, Daejeon 300-824, Republic of Korea \\ ${ }^{7}$ Namhae Sub-Station, National Horticultural Research Institute, RDA, Namhae, 668-812, \\ Republic of Korea
}

Correspondence Young-Hyo Chang yhchang@kribb.re.kr

\begin{abstract}
A Gram-positive, rod-shaped, endospore-forming bacterium, designated strain BLB-1 ${ }^{\top}$, was isolated from samples of tidal flat sediment from the Yellow Sea. 16S rRNA gene sequence analysis demonstrated that the isolate belonged to the Bacillus rRNA group 2 and was closely related to Bacillus massiliensis CIP $108446^{\top}$ (97.4\%), Bacillus odysseyi ATCC PTA-4993 ${ }^{\top}$ (96.7\%), Lysinibacillus fusiformis DSM $2898^{\top}$ (96.2\%) and Lysinibacillus boronitolerans DSM $17140^{\top}(95.9 \%)$. Sequence similarities with related species in other genera, including Caryophanon, Sporosarcina and Solibacillus, were $<96.1 \%$. Chemotaxonomic data supported the affiliation of strain BLB-1 ${ }^{\top}$ with the genus Lysinibacillus. The major menaquinone was MK-7, the cell-wall sugars were glucose and xylose, the cell-wall peptidoglycan type was $A 4 \alpha$ (L-Lys-D-Asp), the major polar lipids were diphosphatidylglycerol, phosphatidylglycerol, phosphatidylethanolamine and several unknown phospholipids, and the major fatty acids were anteiso- $\mathrm{C}_{15: 0}(35.6 \%)$, iso- $\mathrm{C}_{15: 0}(25.6 \%)$ and anteiso- $\mathrm{C}_{17: 0}(16.5 \%)$. The most closely related species, Bacillus massiliensis and Bacillus odysseyi, were also assigned to this genus based on phylogenetic analysis and phenotypic data. The results of DNA-DNA hybridizations and phenotypic tests supported the differentiation of all three taxa from species of the genus Lysinibacillus with validly published names. Thus, strain BLB $-1^{\top}\left(=\mathrm{KCTC} 13296^{\top}=\mathrm{JCM}\right.$ $15800^{\top}$ ) represents a novel species, for which the name Lysinibacillus sinduriensis sp. nov. is proposed. It is also proposed that Bacillus massiliensis CIP $108446^{\top}\left(=4400831^{\top}\right.$
\end{abstract}




\begin{abstract}
$=$ CCUG $49529^{\top}=$ KCTC $\left.13178^{\top}\right)$ and Bacillus odysseyi NBRC $100172^{\top}\left(=34 \mathrm{hs}-1^{\top}=\right.$ ATCC $^{\top}$ PTA $-4993^{\top}=$ NRRL B-3064 $1^{\top}=$ DSM $18869^{\top}=$ CIP $108263^{\top}=\mathrm{KCTC}^{\top} 3961^{\top}$ ) be transferred to the genus Lysinibacillus as Lysinibacillus massiliensis comb. nov. and Lysinibacillus odysseyi comb. nov., respectively.
\end{abstract}

Species of the genus Bacillus have been isolated from diverse habitats (Nakamura et al., 2002; La Duc et al., 2004; Heyrman et al., 2005; Glazunova et al., 2006). Based on genotypic analysis and chemotaxonomic data, several spore-forming species in the Bacillus rRNA group 2 (Ash et al., 1991) were reclassified into the following novel taxa: Sporosarcina globispora, Sporosarcina psychrophila and Sporosarcina pasteurii (Yoon et al., 2001); Lysinibacillus fusiformis and Lysinibacillus sphaericus (Ahmed et al., 2007); Viridibacillus arvi, Viridibacillus arenosi and Viridibacillus neidei (Albert et al., 2007); Solibacillus silvestris (Krishnamurthi et al., 2009); Rummeliibacillus pycnus (Vaishampayan et al., 2009); and Psychrobacillus insolitus, Psychrobacillus psychrotolerans and Psychrobacillus psychrodurans (Krishnamurthi et al., 2010). Several investigators have suggested that some species placed within the Bacillus rRNA group 2 do not belong to the genus Bacillus and that they should be reclassified as novel genera or transferred to existing genera within the group (Farrow et al., 1994; Yoon et al., 2001; Ahmed et al., 2007; Albert et al., 2007; Krishnamurthi et al., 2009). Based on polyphasic taxonomic data, a new genus, Lysinibacillus, was recently proposed for the reclassification of two species assigned to the genus Bacillus and a newly described species (Ahmed et al., 2007). At the time of publication, the genus Lysinibacillus contained six species with validly published names: Lysinibacillus boronitolerans, Lysinibacillus fusiformis, Lysinibacillus sphaericus (Ahmed et al., 2007), Lysinibacillus parviboronicapiens (Miwa et al., 2009), Lysinibacillus xylanilyticus (Lee et al., 2010) and Lysinibacillus macroides (Coorevits et al., 2012). The taxonomic positions of Bacillus massiliensis and Bacillus odysseyi indicate that these species are phylogenetically distantly related to Rummelibacillus pycnus or Solibacillus silvestris. This issue has been discussed previously (Ahmed et al., 2007; Krishnamurthi et al., 2009) but no proposal has yet been made for transferring these species into new or existing genera. In the present study, we used a polyphasic taxonomic approach to re-evaluate the taxonomic position of B. massiliensis and B. odysseyi, as well as characterize a strain isolated from tidal flat sediments during this study, identifying it as a novel species.

A novel strain, designated BLB- $1^{\mathrm{T}}$, was isolated from $50 \mathrm{~g}$ samples of tidal flat sediment collected at a depth of $20 \mathrm{~cm}$

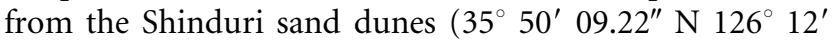
$11.90^{\prime \prime}$ E) at Tae-An on the Yellow Sea coast, Republic of Korea. Samples were individually placed into $50 \mathrm{ml}$ sterile tubes (Corning) and pooled into an anaerobic pouch (GasPak, Becton Dickinson) in an icebox, before transporting them to the laboratory for immediate processing. Each sample was serially diluted in saline solution $(0.85 \%, \mathrm{w} / \mathrm{v}$, $\mathrm{NaCl}$ ), spread onto tryptic soy broth medium (TSB; $\mathrm{pH}$ 7.3; Difco) solidified with $15.0 \mathrm{~g} \mathrm{l}^{-1}$ agar (TSBA) and incubated at $30{ }^{\circ} \mathrm{C}$ for $48 \mathrm{~h}$. The strain was subcultured several times to obtain a purified culture, before further characterization. Reference strains used in this study included B. massiliensis KCTC $13178^{\mathrm{T}}$, B. odysseyi KCTC $3961^{\mathrm{T}}$, L. boronitolerans KCTC $13709^{\mathrm{T}}$, L. fusiformis KCTC $3454^{\mathrm{T}}$ and L. sphaericus KCTC $3346^{\mathrm{T}}$. Strains were cultured routinely on TSBA medium under the same conditions before storage at $-80{ }^{\circ} \mathrm{C}$ as skimmed milk (Difco) suspensions $(10 \%, \mathrm{w} / \mathrm{v})$.

To determine the differential phenotypic properties of the novel isolate, strain $\mathrm{BLB}-1^{\mathrm{T}}$ and several reference strains were subjected to morphological, physiological and biochemical analyses (Chang et al., 2002, 2008). All tests were performed using fresh cultures of purified strains grown under the same conditions. Cell morphology was examined by bright-field microscopy (Nikon Optiphot-2), phasecontrast microscopy (Nikon 80i) and electron microscopy (S4300N, Hitachi). For the electron microscopic analysis, cells were fixed in a $2.5 \%(\mathrm{v} / \mathrm{v})$ paraformaldehyde/glutaraldehyde mixture, sputter-coated with gold (SC502, Polaron) and observed using a scanning electron microscope (S4300N, Hitachi). Cells were negatively stained with $1 \%(\mathrm{w} / \mathrm{v})$ uranyl acetate and the flagella type was observed using a model CM-20 transmission electron microscope (Philips) (Chang et al., 2002). Growth at $10-60{ }^{\circ} \mathrm{C}$ and in $0-7 \%(\mathrm{w} / \mathrm{v}) \mathrm{NaCl}(0.5 \%$ increments $)$ was determined over a period of 3-7 days in TSB medium. Growth was assessed by monitoring $\mathrm{OD}_{600}$ using a spectrophotometer (Bio$\mathrm{Rad}$ ). The $\mathrm{pH}$ range for growth was determined in buffered TSB medium at $30{ }^{\circ} \mathrm{C}$ using a $500 \mathrm{ml}$ flask (Corning) containing $250 \mathrm{ml}$ medium at $\mathrm{pH} \mathrm{4-9}$ (increments of $0.5 \mathrm{pH}$ units). The medium was buffered using one of three different solutions: $50 \mathrm{mM}$ succinic acid/ $\mathrm{NaOH}$ (pH 4-6), $100 \mathrm{mM} \quad \mathrm{Na}_{2} \mathrm{HPO}_{4} / \mathrm{NaH}_{2} \mathrm{PO}_{4} \quad(\mathrm{pH} 6-8)$ or $50 \mathrm{mM}$ 2-amino-2-methyl-1,3-propanediol/ $\mathrm{HCl} \quad(\mathrm{pH} 8-$ 9). Motility was tested in TSB medium containing $0.4 \%$ agar. Gram reaction, enzyme activity, carbohydrate utilization and hydrolysis reactions were conducted using standard methods (Smibert \& Krieg, 1994; Chang et al., 2002). The catalase and oxidase activity, indole production, nitrate reduction, $\mathrm{KOH}$ test and endospore staining were conducted as previously described (Smibert \& Krieg, 1994). Hydrolysis of casein and starch were tested on skimmed milk agar and starch agar, respectively. Gelatin liquefaction was determined by inoculation on $12 \%$ gelatin followed by incubation for 7 days. Arginine dihydrolase, lysine decarboxylase, ornithine decarboxylase and urease, utilization 
of citrate and amino acids activities, the Voges-Proskauer test and utilization of various carbohydrates were determined as previously described (Smibert \& Krieg, 1994; Chang et al., 2002). A variety of tests to determine biochemical characteristics were also performed using API 20 $\mathrm{E}$, API ZYM, and API $50 \mathrm{CH}$ B/E strips (bioMérieux), and the Biolog GP2 MicroPlate system (Biolog).

Strain BLB- $1^{\mathrm{T}}$ was catalase-positive and oxidase-negative. Catalase activity was also present in $B$. massiliensis and $B$. odysseyi, whereas oxidase activity was not detected in strain B. odysseyi (La Duc et al., 2004; Glazunova et al., 2006). At the time of publication, $L$. parviboronicapiens was the only oxidase-negative species out of all the species in the genus Lysinibacillus (Miwa et al., 2009). No sugars were fermented in the API $50 \mathrm{CH}$ strips with strain BLB- $1^{\mathrm{T}}$ or B. odysseyi, which matched the results of tests performed with B. massiliensis (Glazunova et al., 2006). Strain BLB- $1^{\mathrm{T}}$ and $B$. massiliensis cells produced spherical endospores whereas $B$. odysseyi produced round endospores in the terminal position. Detailed phenotypic characteristics of strain BLB- $1^{\mathrm{T}}$ are presented in Table 1 and the species description.
A nearly complete $16 \mathrm{~S}$ rRNA gene sequence (1413 bp) for strain $\mathrm{BLB}-1^{\mathrm{T}}$ was obtained using the method of Chang et al. (2008). Preliminary sequence comparison was conducted against $16 \mathrm{~S}$ rRNA gene sequences of species with validly published names retrieved from the EzTaxon and GenBank databases of prokaryotic type strains. The nearly complete 16S rRNA gene sequences of the strains were aligned manually against those of closely related representatives from other genera based on the bacterial 16S rRNA secondary structure model (Woese et al., 1980). The regions available for all sequences (conserved and variable regions) showed unambiguous alignment and they were used to reconstruct phylogenetic trees. Sequences were aligned and neighbour-joining (Saitou \& Nei, 1987) analysis was performed using the PHYLIP (Felsenstein, 1993) and jPHYDIT (Jeon et al., 2005) programs. Phylogenetic trees were also reconstructed using the maximum-likelihood (Felsenstein, 1981) and maximum-parsimony (Fitch, 1971) methods. An evolutionary distance matrix for the neighbour-joining tree was generated according to the model of Jukes \& Cantor (1969). The reliability of each tree was evaluated by bootstrap analysis (Felsenstein, 1985) based on 1000 resamplings.

Table 1. Differential characteristics of the strain BLB-1 ${ }^{\top}$ and closely related species

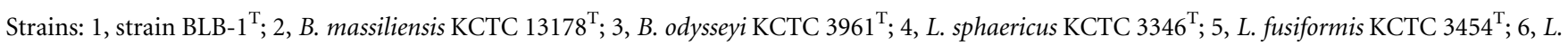
boronitolerans KCTC $13709^{\mathrm{T}}$. Symbols: + , positive; -, negative; w, weakly positive. All strains were catalase-positive. All data are from this study. AMP, adenosine monophosphate; UMP, uridine monophosphate.

\begin{tabular}{|c|c|c|c|c|c|c|}
\hline Characteristic & 1 & 2 & 3 & 4 & 5 & 6 \\
\hline Temperature range for growth & $15-45$ & $25-45$ & $25-42$ & $10-40$ & $17-40$ & $16-45$ \\
\hline Oxidase & - & + & - & + & + & + \\
\hline Voges-Proskauer test & - & + & + & - & - & + \\
\hline \multicolumn{7}{|l|}{ Hydrolysis of: } \\
\hline Arginine dihydrolase & - & + & - & - & - & + \\
\hline Trypsin & + & - & - & $\mathrm{w}$ & - & - \\
\hline$\alpha$-Chymotrypsin & $\mathrm{w}$ & - & + & + & + & $\mathrm{w}$ \\
\hline Acid phosphatase & + & - & - & - & - & + \\
\hline Naphthol-AS-BI-phosphohydrolase & + & + & - & + & $\mathrm{w}$ & + \\
\hline$\alpha$-Hydroxybutyrate & - & - & + & - & - & + \\
\hline L-Alanine & - & - & + & + & + & + \\
\hline Glycyl-L-glutamate & - & - & + & + & + & + \\
\hline Adenosine & - & - & + & + & + & + \\
\hline $2^{\prime}$-Deoxyadenosine & - & - & - & + & + & + \\
\hline Inosine & - & - & + & + & + & + \\
\hline AMP & - & - & + & + & + & + \\
\hline UMP & - & - & + & + & + & + \\
\hline Dextrin & - & + & + & + & - & + \\
\hline
\end{tabular}


Phylogenetic analysis demonstrated that the isolate belonged to the Bacillus rRNA group 2, members of which are closely related to $B$. massiliensis CIP $108446^{\mathrm{T}}$ and $B$. odysseyi NBRC $100172^{\mathrm{T}}$. However, strain BLB- $1^{\mathrm{T}}$ could be clearly distinguished from all species with validly published names in the genus Bacillus. Strain BLB- ${ }^{\mathrm{T}}$, B. massiliensis and $B$. odysseyi were closely related and were grouped in a single clade in the neighbour-joining tree containing type strains of species belonging to this group (Fig. 1). Furthermore, all three taxa and species of the genus Lysinibacillus were separated into a different clade from members of the genera Solibacillus, Rummeliibacillus and Viridibacillus. The distinct branch formed by the radiation of this group did not depend on the tree-making algorithm used and was supported by a $96 \%$ bootstrap value (Fig. S1, available in IJSEM Online). The phylogenetic analysis strongly indicated that the three taxa represent novel species belonging to the genus Lysinibacillus.

The closest phylogenetic relatives to strain BLB- $1^{\mathrm{T}}$ were $B$. massiliensis CIP $108446^{\mathrm{T}}$ (97.4\% 16S rRNA gene sequence similarity) followed by B. odysseyi NBRC $100172^{\mathrm{T}}$ (96.7\%), L. fusiformis DSM $2898^{\mathrm{T}}$ (96.2\%), L. sphaericus DSM $28^{\mathrm{T}}$ $(96.1 \%)$ and L. boronitolerans DSM $17140^{\mathrm{T}}(95.9 \%)$. The recently described species $L$. parviboronicapiens $(95.7 \%), L$. xylanilyticus (97.2\%; Lee et al., 2010) and L. macroides (96.2\%; Coorevits et al., 2012) appeared to be distant phylogenetic relatives of strain BLB- $1^{\mathrm{T}}$. Sequence similarity alues between strain BLB- $1^{\mathrm{T}}$ and other species in the genera Caryophanon, Sporosarcina, Solibacillus, Rummeliibacillus and Viridibacillus were $<96.1 \%$. Therefore, additional DNA-DNA hybridization was performed to more accurately differentiate these closely related species (Tindall et al., 2010).

DNA-DNA hybridization was performed as previously described (Ezaki et al., 1989) using photobiotin-labelled probes at $45{ }^{\circ} \mathrm{C}$ with a Fluoroskan Ascent Fluorescent plate reader (Thermo Life Sciences). Three replicates of each sample were tested. The DNA-DNA hybridization values between strain BLB- $1^{\mathrm{T}}$ and B. massiliensis KCTC $13178^{\mathrm{T}}$, L. sphaericus KCTC $3346^{\mathrm{T}}$, B. odysseyi KCTC $3961^{\mathrm{T}}$, L. fusiformis KCTC $3454^{\mathrm{T}}$ and L. boronitolerans KCTC $13709^{\mathrm{T}}$ were $24.9,24.1,21.0,20.5$ and $18.3 \%$, respectively. These values are much lower than the suggested threshold value for species delineation (Wayne et al., 1987) and indicate that the isolate represents a novel species that is distinct from closely related species.

To determine the DNA G $+\mathrm{C}$ content, DNA was analysed by real-time PCR (Thermocycler, Bio-Rad) with SYBR Green I, according to a previously described fluorometric method (Gonzalez \& Saiz-Jimenez, 2002). The relative values were calculated based on E. coli KCTC $2441^{\mathrm{T}}$ DNA $\left(50.8 \mathrm{~mol} \%, T_{\mathrm{m}}\right)$ as a standard. The mean DNA G+C contents of strains BLB- $1^{\mathrm{T}}$, B. massiliensis KCTC $13178^{\mathrm{T}}$ and B. odysseyi KCTC $3961^{\mathrm{T}}$ were 35.9, 36.3 and $35.6 \mathrm{~mol} \%$, respectively. These data corresponded more closely with the typical ranges of members of the genera Lysinibacillus (35-38 mol\%; Ahmed et al., 2007), Kurthia (36-38 mol\%; Keddie \& Jones, 1992), Viridibacillus (35-40.4 mol\%; Albert

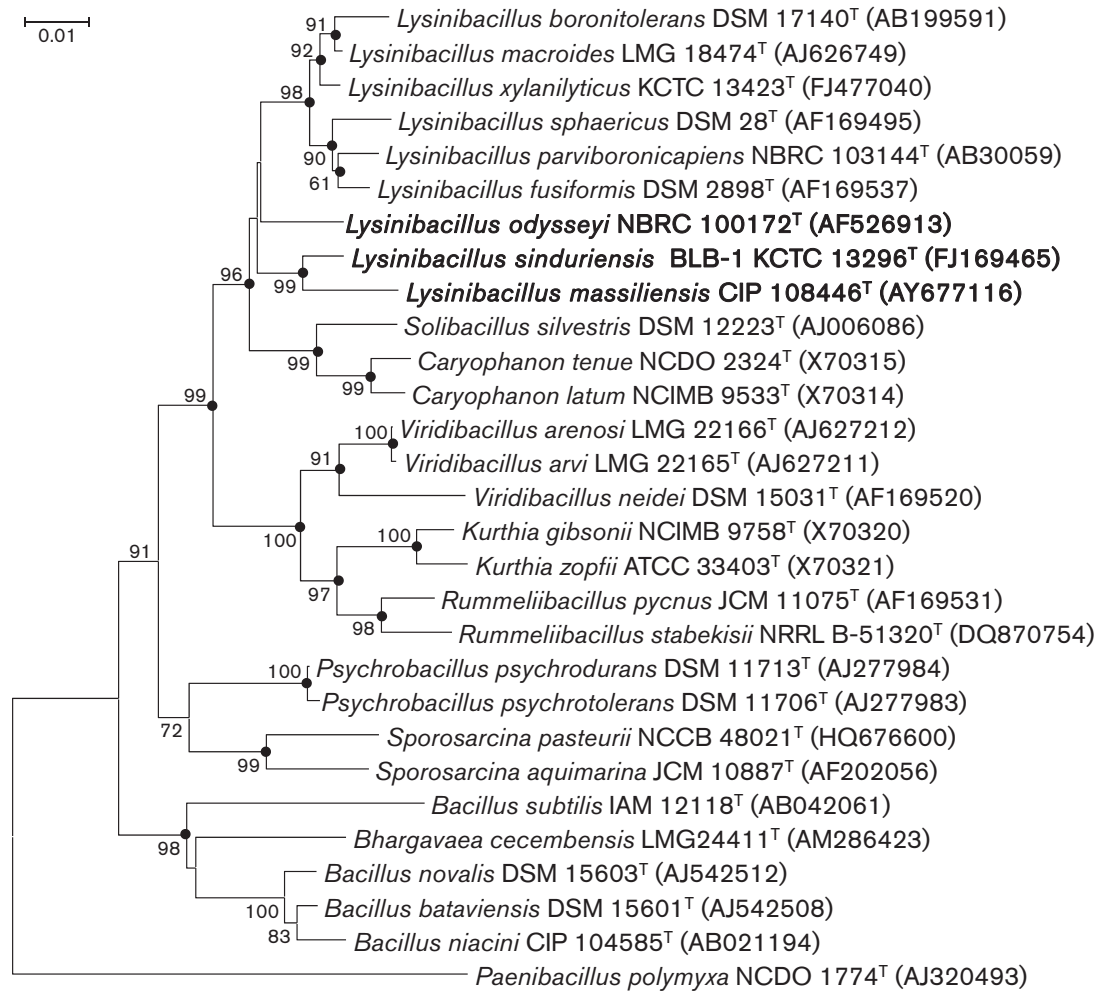

Fig. 1. Phylogenetic tree inferred by neighbour-joining method based on 16S rRNA gene sequences (1413 bp). The tree shows the relationship between strain BLB-1 ${ }^{\top}$ and closely related taxa. Bootstrap values $>50 \%$ (based on 1000 replications) are shown at branch points. Filled circles indicate that the corresponding nodes were also recovered in the tree generated with the maximum-parsimony algorithm. Bar, 0.01 substitutions per nucleotide position. 
et al., 2007) and Bacillus (32-69 mol\%; Heyrman et al., 2005) rather than the genera Sporosarcina (40-42 mol\%; Yoon et al., 2001) or Caryophanon (44-46 mol\%; Claus et al., 1992).

The cellular fatty acid profiles of strain BLB- $1^{\mathrm{T}}$ and closely related strains grown on TSBA medium at $28{ }^{\circ} \mathrm{C}$ for $48 \mathrm{~h}$ were determined according to the Sherlock Microbial Identification System (MIDI). The fatty acids were separated using an automated GC system (model 6890N and 7683 Autosampler; Agilent) and identified with the associated software package version 4.0 (Library TSBA 40, MIDI). The fatty acid profile of strain BLB- $1^{\mathrm{T}}$ (Table 2) was characterized by high proportions of saturated branched fatty acids, such as anteiso- $\mathrm{C}_{15: 0}(35.6 \%)$, iso- $\mathrm{C}_{15: 0}$ $(25.6 \%)$ and anteiso- $\mathrm{C}_{17: 0}(16.5 \%)$. Significant differences in the relative amounts of iso- $\mathrm{C}_{15: 0}$ and anteiso- $\mathrm{C}_{17: 0}$ were found between strain BLB- $1^{\mathrm{T}}$ and its closest relatives and these characteristics could be used to differentiate the novel isolate from related species (Kämpfer et al., 1994; Ahmed et al., 2007). The major fatty acids detected in strain BLB- $1^{\mathrm{T}}$, iso- and anteiso- $\mathrm{C}_{15: 0}$, have also been detected as major components in $B$. subtilis and members of the genera Lysinibacillus, Viridibacillus, Rummeliibacillus and Kurthia (Shaw \& Keddie, 1983; Kämpfer et al., 2006; Ahmed et al., 2007; Albert et al., 2007). In contrast, iso- $\mathrm{C}_{15: 0}$ and iso- $\mathrm{C}_{16: 1}$ were detected as the major fatty acids in members of the genus Solibacillus (Krishnamurthi et al., 2009).

Respiratory quinones were determined as described previously (Komagata \& Suzuki, 1987) using TLC and HPLC. The major menaquinone was MK-7 in strains BLB- $1^{\mathrm{T}}, B$.

Table 2. Cellular fatty acid compositions of strain BLB-1 ${ }^{\top}$ and closely related species

Strains: 1, strain BLB-1 ${ }^{\mathrm{T}}$; 2, B. massiliensis KCTC $13178^{\mathrm{T}} ; 3$, B. odysseyi KCTC $3961^{\mathrm{T}}$; 4, L. sphaericus KCTC $3346^{\mathrm{T}}$; 5, L. fusiformis KCTC $3454^{\mathrm{T}} ; 6$, L. boronitolerans KCTC $13709^{\mathrm{T}}$. Values are percentages of total fatty acids. $t$, Trace amount $(<1.0 \%) ;-$, not detected. All data are from this study.

\begin{tabular}{|c|c|c|c|c|c|c|}
\hline Fatty acid & 1 & 2 & 3 & 4 & 5 & 6 \\
\hline iso- $\mathrm{C}_{14: 0}$ & 1.9 & 4.1 & 2.2 & 3.5 & 1.1 & 2.1 \\
\hline iso- $\mathrm{C}_{15: 0}$ & 25.6 & 54.3 & 50.4 & 53.5 & 59.7 & 59.9 \\
\hline anteiso- $\mathrm{C}_{15: 0}$ & 35.6 & 10.9 & 7.1 & 3.3 & 10.5 & 7.4 \\
\hline $\mathrm{C}_{15: 0}$ & 1.2 & 5.4 & - & - & - & $\mathrm{t}$ \\
\hline $\mathrm{C}_{16: 1} \omega 7 c$ alcohol & 4.4 & 1.8 & 12.7 & 17.4 & 7.8 & 13.2 \\
\hline iso- $\mathrm{C}_{16: 0}$ & 4.3 & 15.0 & 11.3 & 8.4 & 4.1 & 3.2 \\
\hline $\mathrm{C}_{16: 1} \omega 11 c$ & 1.1 & $\mathrm{t}$ & 2.1 & 1.8 & 2.5 & 1.5 \\
\hline iso- $\mathrm{C}_{17: 1} \omega 10 c$ & 1.3 & $\mathrm{t}$ & 4.3 & 4.9 & 3.9 & 4.7 \\
\hline iso- $\mathrm{C}_{17: 0}$ & 3.1 & 2.8 & 5.3 & 4.2 & 3.7 & 2.8 \\
\hline anteiso- $\mathrm{C}_{17: 0}$ & 16.5 & 3.2 & 1.9 & $\mathrm{t}$ & 2.6 & 1.2 \\
\hline Summed feature $4^{*}$ & 3.4 & - & 1.2 & 1.2 & 2.6 & 1.8 \\
\hline
\end{tabular}

${ }^{*}$ Summed features represent groups of two or three fatty acids that could not be separated by GC using the Microbial Identification System. Summed feature 4 comprises iso- $\mathrm{C}_{17: 1} \mathrm{I}$ and/or anteiso- $\mathrm{C}_{17: 1} \mathrm{~B}$. massiliensis KCTC $13178^{\mathrm{T}}$ and B. odysseyi KCTC $3961^{\mathrm{T}}$, which corresponded with that found in members of the genus Lysinibacillus. However, this characteristic differed in phylogenetically closely related members of the genera Caryophanon, which contained MK-6 as the predominant menaquinone (Ahmed et al., 2007; Krishnamurthi et al., 2009), and Viridibacillus, which contained MK-8 as the predominant menaquinone (Albert et al., 2007).

Cell-wall sugar analysis of the whole-cell hydrolysates was performed as described by Schleifer \& Kandler (1972) using TLC with cellulose plates (Merck). Glucose and xylose were the predominant cell-wall sugars in strain $\mathrm{BLB}-1^{\mathrm{T}}$. The closest relative, B. massiliensis KCTC $13178^{\mathrm{T}}$, produced similar results to strain BLB- ${ }^{\mathrm{T}}$, whereas $B$. odysseyi $\mathrm{KCTC}$ $3961^{\mathrm{T}}$ was different, with only xylose as the predominant cell-wall sugar.

Peptidoglycan structure was determined as described previously (Schleifer \& Kandler, 1972; Schleifer, 1985) with modification of the TLC using cellulose plates rather than paper chromatography. Quantitative analysis of amino acids in the peptidoglycan was performed by GC according to the method of MacKenzie (1987). Strain BLB-1 ${ }^{\mathrm{T}}$ contained peptidoglycan with alanine, glutamic acid, lysine and aspartic acid as diagnostic amino acids in a molar ratio of $1.3: 1.0: 0.9: 1.0$, respectively. The close relatives $B$. massiliensis KCTC $13178^{\mathrm{T}}$ and B. odysseyi KCTC $3961^{\mathrm{T}}$ had similar amino acid molar ratios. The peptidoglycan type A4 $\alpha$ L-Lys-D-Asp (A11.31; DSMZ, 2001) was very similar to that found in species of the genera Lysinibacillus, Kurthia and Viridibacillus (Shaw \& Keddie, 1983; Ahmed et al., 2007; Krishnamurthi et al., 2009). By contrast, the type species of the genus Bacillus, B. subtilis, is known to possess meso-diaminopimelic acid in the cell-wall peptidoglycan (Schleifer \& Kandler, 1972). These data strongly indicate that B. massiliensis KCTC $13178^{\mathrm{T}}$ and B. odysseyi KCTC $3961^{\mathrm{T}}$ do not belong to the genus Bacillus and instead they should be reclassified into new or existing genera. We propose that these species be transferred to the genus Lysinibacillus.

Polar lipids were extracted from $100 \mathrm{mg}$ freeze-dried cell material and separated using a two-stage method as described previously (Tindall, 1990). Polar lipid analysis was conducted by the DSMZ Identification Service and Dr Brian Tindall (DSMZ Braunschweig, Germany). TLC plates were stained with $5 \%$ molybdophosphoric acid to detect all the lipids. The major polar lipids in strain BLB- ${ }^{\mathrm{T}}$ and B. odysseyi KCTC $3961^{\mathrm{T}}$ were diphosphatidylglycerol (DPG), phosphatidylglycerol (PG), and phosphatidylethanolamine (PE). Moderate amounts of phospholipid (PL2) and minor amounts of two phospholipids (PL1, PL4) and an unknown lipid (L1) were also detected. B. odysseyi KCTC $3961^{\mathrm{T}}$ also contained PL5, L3 and L4 (Fig. 2). By contrast, $B$. massiliensis KCTC $13178^{\mathrm{T}}$ showed a significantly different profile with major components of DPG and PG, moderate amounts of two glycolipids (GL1, 2) and minor amounts of PL1, 2, 3 and 4 and L1, but no PE was detected. Glycolipids 


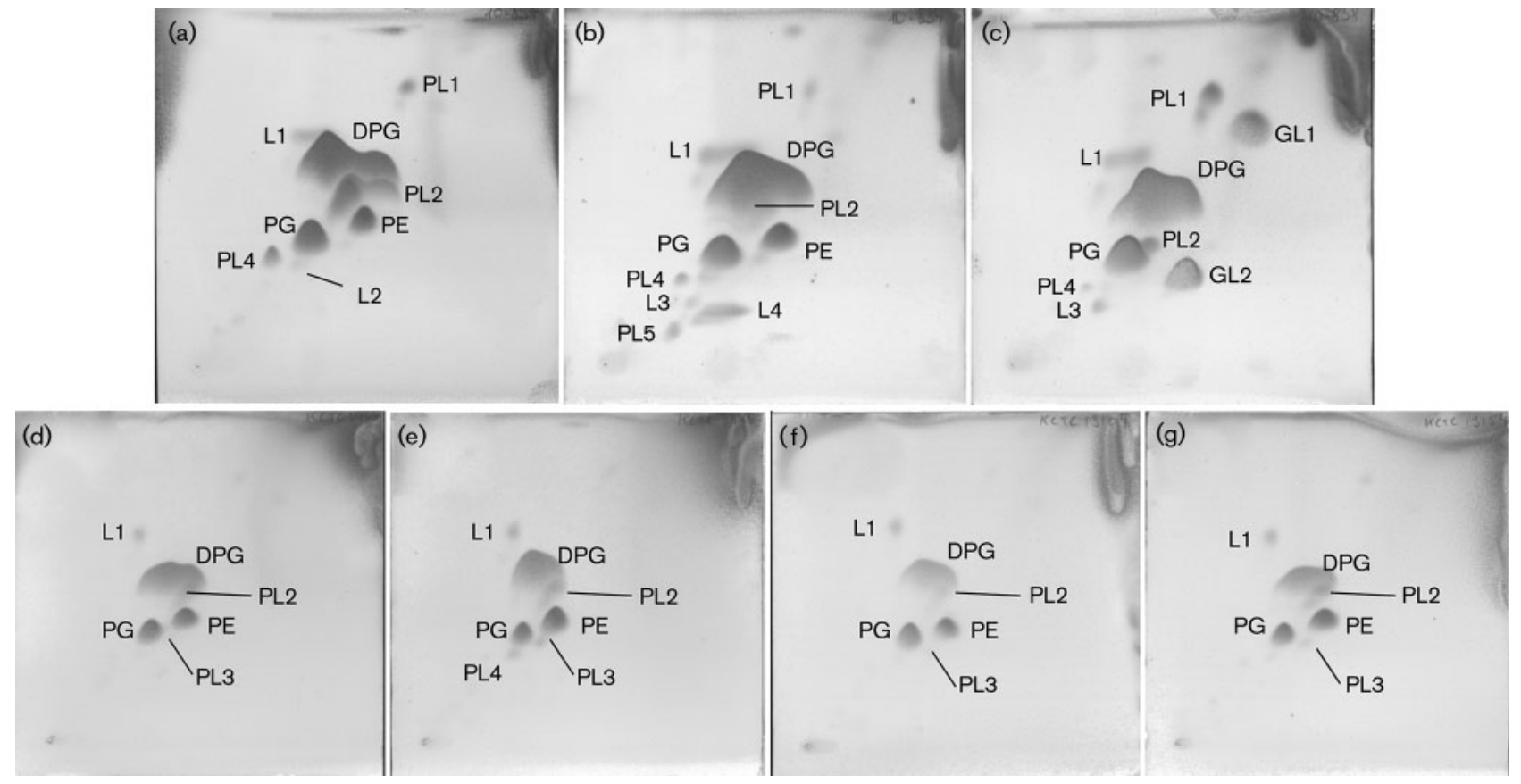

Fig. 2. Polar lipid profiles after separation by two-dimensional TLC. (a) Strain BLB-1 ${ }^{\top}$; (b) $L$. odysseyi $K C T C 3961^{\top}$; (c) $L$. massiliensis KCTC $13178^{\top}$; (d) L. fusiformis KCTC $3454^{\top}$; (e) L. sphaericus KCTC $3346^{\top}$; (f) L. boronitolerans KCTC $13709^{\top}$; (g) L. parviboronicapiens KCTC $13154^{\top}$. DPG, diphosphatidylglycerol; PG, phosphatidylglycerol; PE, phosphatidylethanolamine; PL1-5, unidentified phospholipids; GL1-2, unidentified glycolipids; L1-4, unidentified lipid.

have also been reported in members of the genera Bacillus, Paenibacillus and Cohnella (Kämpfer et al., 2006), where the absence of PE is used to differentiate species. The profiles of three strains were compared with B. subtilis (Kämpfer et al., 2006) and significant differences were observed, i.e. the presence of gentiobiosyldiacylglycerol (GBG) and aminophospholipids (APL) in B. subtilis. The phylogenetic relative, Solibacillus silvestris (Krishnamurthi et al., 2009) differed from the three strains in terms of the presence of phosphatidylserine (PS). In addition, the presence of aminolipids (AL) was reported in the genus Viridibacillus (Albert et al., 2007), whereas AL and APL are also found in the genus Rummeliibacillus (Vaishampayan et al., 2009). The closest phylogenetic relatives, species of the genus Lysinibacillus, matched the lipid profiles of strains BLB- $1^{\mathrm{T}}, B$. odysseyi KCTC $3961^{\mathrm{T}}$ and B. massiliensis KCTC $13178^{\mathrm{T}}$ because they shared DPG and PG as major components (Ahmed et al., 2007). However, the ninhydrin-positive phosphoglycolipids (NPG) that are typical of members of the genus Lysinibacillus were not detected in the strains investigated in this study.

This investigation had to be expanded to include more detailed polar lipid profiles for the type species of the genus Lysinibacillus. Thus, comparative analyses of $L$. boronitolerans KCTC $13709^{\mathrm{T}}\left(=\mathrm{DSM} 17140^{\mathrm{T}}\right)$, L. fusiformis KCTC $3454^{\mathrm{T}}\left(=\mathrm{DSM} 2898^{\mathrm{T}}\right)$ and L. sphaericus KCTC $3346^{\mathrm{T}}\left(=\mathrm{DSM} 28^{\mathrm{T}}\right)$ were performed to better understand their lipid profiles. The major profiles of these three species contained DPG, PG and PE, as well as minor amounts of PL2, PL3 and L1 (Fig. 2). L. sphaericus KCTC $3346^{\mathrm{T}}$ also possessed PL4. NPG was not detected in these three species, which was in agreement with the lipid profile of BLB- $1^{\mathrm{T}}$ determined in the current study. No spots had the same $\mathrm{R}_{\mathrm{f}}$ value as the major component NPG reported by Ahmed et al. (2007). L. xylanilyticus and L. macroides also lacked the previously reported NPG (Lee et al., 2010; Coorevits et al., 2012). Thus, the affiliation of these species differs from the description of the genus Lysinibacillus in terms of their polar lipid profiles (Ahmed et al., 2007), which suggests that the original description of the genus needs to be amended based on the current analysis. The profiles of strains BLB- $1^{\mathrm{T}}, B$. odysseyi KCTC $3961^{\mathrm{T}}$ and B. massiliensis KCTC $13178^{\mathrm{T}}$ were far more complex than those of previously reported species of the genus Lysinibacillus (Ahmed et al., 2007; Miwa et al., 2009; Lee et al., 2010). Furthermore, the presence of GL and the lack of PE in B. massiliensis KCTC $13178^{\mathrm{T}}$ showed that it had a significantly different profile from its closest relative strain, as well as from BLB- $1^{\mathrm{T}}$ and species of the genus Lysinibacillus. This difference could be used to differentiate the species from closely related taxa but was insufficient to exclude it from the genus Lysinibacillus. In conclusion, the polar lipid profiles indicate that the genus Lysinibacillus is as heterogeneous as the genera Bacillus and Paenibacillus (Kämpfer et al., 2006).

In conclusion, the novel isolate BLB- $1^{\mathrm{T}}, B$. massiliensis KCTC $13178^{\mathrm{T}}$, and B. odysseyi KCTC $3961^{\mathrm{T}}$ all possess 
peptidoglycan type A4 $\alpha$ (L-Lys-D-Asp) and they share this characteristic with members of the genus Lysinibacillus (Ahmed et al., 2007). The phylogenetic analysis (Fig. 1) also showed that all three taxa, along with species of the genus Lysinibacillus, belong to the same clade within the Bacillus rRNA group 2. Based on these data, it is reasonable to assign the three taxa to the genus Lysinibacillus. The data presented in this study also show that the isolated strain BLB- $1^{\mathrm{T}}$ can be differentiated from other members of the genus Lysinibacillus and represents a novel species, for which the name Lysinibacillus sinduriensis sp. nov. is proposed. The chemotaxonomic and phylogenetic analyses also demonstrated that B. massiliensis and B. odysseyi should be transferred to the genus Lysinibacillus with the names Lysinibacillus massiliensis comb. nov. and Lysinibacillus odysseyi comb. nov., respectively.

\section{Emended description of the genus Lysinibacillus Ahmed et al. 2007}

The description is as given previously (Ahmed et al., 2007) with the following amendments. Oxidase activity is variable. Major cellular fatty acids iso- $\mathrm{C}_{15: 0}$ or anteiso- $\mathrm{C}_{15: 0}$ are present. The polar lipid profiles contain DPG, PG and PE as predominant lipids, with varying numbers of unidentified polar lipids and amino-group-containing lipids. Some species do not contain PE and instead contain unidentified glycolipids as major components.

\section{Description of Lysinibacillus sinduriensis sp. nov.}

Lysinibacillus sinduriensis (sin.du.ri.en'sis. N.L. masc. adj. sinduriensis pertaining to the Sinduri, Republic of Korea, geographical origin of the type strain of the species).

Cells are Gram-positive, strictly aerobic, terminal spherical spore-forming, straight and club-shaped rods $(0.5-1.2 \times$ $0.7-3.5 \mu \mathrm{m}$ ) with swollen sporangium and are motile by peritrichous flagella. Colonies grown on TSBA medium are circular, convex, undulate, greyish white and $3 \mathrm{~mm}$ in diameter. Cells grow at $15-45{ }^{\circ} \mathrm{C}$ (optimum $30{ }^{\circ} \mathrm{C}$ ), at pH 5-9 (optimum pH 7) and in $0-5 \%(w / v) ~ N a C l$ but not in $6 \%(\mathrm{w} / \mathrm{v}) \mathrm{NaCl}$. Negative for nitrate reduction, oxidase, arginine dihydrolase, lysine decarboxylase, ornithine decarboxylase, urease and tryptophan deaminase activities, citrate utilization, Voges-Proskauer test, production of $\mathrm{H}_{2} \mathrm{~S}$, indole and acetoin and hydrolysis of casein and starch; positive for gelatinase and catalase. No sugar is fermented in the API $50 \mathrm{CH}$ strips, using $\mathrm{CHB} / \mathrm{E}$ suspension medium. Oxidizes $\alpha$-ketovaleric acid and pyruvic acid methyl ester but not acetate, pyruvate, $\alpha$ - and $\beta$-hydroxybutyrate, methyl pyruvate, L-alanine, glycyl-L-glutamate, adenosine, 2'-deoxyadenosine, inosine, adenosine monophosphate, uridine monophosphate or dextrin. Negative for alkaline phosphatase, lipase, valine arylamidase, cystine arylamidase, $\alpha$ - and $\beta$-galactosidase, $\beta$-glucuronidase, $\alpha$ and $\beta$-glucosidase, $N$-acetyl- $\beta$-glucosaminidase, $\alpha$-mannosidase and $\alpha$-fucosidase activities; positive for esterase, esterase lipase, leucine arylamidase, trypsin, $\alpha$-chymotrypsin, acid phosphatase and naphthol-AS-BI-phosphohydrolase. The major polar lipids are DPG, PG, PE and three unknown phospholipids, PL1, PL2 and PL3. The predominant fatty acids are anteiso- $\mathrm{C}_{15: 0}(35.6 \%)$, iso- $\mathrm{C}_{15: 0}$ $(25.6 \%)$ and anteiso- $\mathrm{C}_{17: 0}(16.5 \%)$. The major cell-wall sugars are glucose and xylose. The cell-wall peptidoglycan contains L-Lys-D-Asp (type A4 $\alpha$ ). The major menaquinone is MK-7.

The type strain, BLB- $1^{\mathrm{T}}\left(=\mathrm{KCTC} 13296^{\mathrm{T}}=\mathrm{JCM} 15800^{\mathrm{T}}\right)$, was isolated from tidal flat sediment in the Shinduri sand dunes of the Yellow Sea, Republic of Korea. The DNA $\mathrm{G}+\mathrm{C}$ content of the type strain is $35.9 \mathrm{~mol} \%$.

\section{Description of Lysinibacillus odysseyi comb. nov.}

Lysinibacillus odysseyi (o.dys.se'yi. L. n. Odyssea the Odyssey; N.L. gen. n. odysseyi pertaining to the Mars Odyssey spacecraft, from which the organism was isolated).

Basonym: Bacillus odysseyi La Duc et al. (2004).

In addition to the description of the type strain given by La Duc et al. (2004), cells are negative for alkaline phosphatase, valine arylamidase, cystine arylamidase, $\alpha$ and $\beta$-galactosidase, $\beta$-glucuronidase, $\alpha$ - and $\beta$-glucosidase, $N$-acetyl- $\beta$-glucosaminidase, $\alpha$-mannosidase, $\alpha$-fucosidase, trypsin, acid phospatase and naphthol-AS-BI-phosphohydrolase activities; positive for esterase, esterase lipase, leucine arylamidase and $\alpha$-chymotrypsin activities. Oxidizes $\alpha$-ketovaleric acid, pyruvic acid methyl ester and dextrin. Negative for oxidase, citrate utilization, urease and tryptophan deaminase activity, hydrolysis of casein and starch and indole production and positive for Voges-Proskauer test and acetoin production. No sugar is fermented in API $50 \mathrm{CH}$ strips using $\mathrm{CHB} / \mathrm{E}$ suspension medium. The cellwall peptidoglycan contains L-Lys-D-Asp (type A4 $\alpha$ ). The major polar lipids are DPG, PG, PE, four unknown phospholipids, PL1, PL2, PL3 and PL4, and an unknown lipid (L1). The predominant fatty acids are iso- $\mathrm{C}_{15: 0}(50.4 \%)$, iso- $\mathrm{C}_{16: 0}(11.3 \%)$ and $\mathrm{C}_{16: 1} \omega 7 c$ alcohol $(12.7 \%)$. The major cell-wall sugar is xylose. The major menaquinone is MK-7. The type strain, 34hs- $1^{\mathrm{T}}$ (=ATCC PTA- $4993^{\mathrm{T}}$ $=$ NRRL B $-30641^{\mathrm{T}}=$ NBRC $100172^{\mathrm{T}}=\mathrm{DSM} 18869^{\mathrm{T}}=\mathrm{CIP}$ $108263^{\mathrm{T}}=$ KCTC $3961^{\mathrm{T}}$ ), was isolated from the surface of the Mars Odyssey spacecraft. The DNA G $+\mathrm{C}$ content of the type strain is $35.6 \mathrm{~mol} \%$.

\section{Description of Lysinibacillus massiliensis comb. nov.}

Lysinibacillus massiliensis (mas.si.li.en'sis. L. masc. adj. massiliensis of Massilia, the ancient Greek and Roman name for Marseille, France, where the type strain was isolated).

Basonym: Bacillus massiliensis Glazunova et al. 2006.

In addition to the description of the type strain given by Glazunova et al. (2006), cells are negative for trypsin, $\alpha$-chymotrypsin, acid phospatase, lipase, valine arylamidase, 
cystine arylamidase, $\alpha$ - and $\beta$-galactosidase, $\beta$-glucuronidase, $\beta$-glucosidase, $N$-acetyl- $\beta$-glucosaminidase, $\alpha$-mannosidase, and $\alpha$-fucosidase activities; positive for alkaline phosphatase, esterase, esterase lipase, leucine arylamidase, acetoin production, $\alpha$-glucosidase, and naphthol-AS-BIphosphohydrolase activities. Negative for nitrate reduction, and hydrolysis of casein and starch. Oxidizes $\alpha$-ketovaleric acid, pyruvic acid methyl ester and dextrin. The cell-wall peptidoglycan contains L-Lys-D-Asp (type A4 $\alpha$ ). The major polar lipids are DPG, PG, three unknown phospholipids, PL1, PL2 and PL3, and two unknown glycolipids, GL1 and GL2. The major cell-wall sugars are glucose and xylose. The major menaquinone is MK-7.

The type strain, $4400831^{\mathrm{T}}\left(=\mathrm{CIP} 108446^{\mathrm{T}}=\mathrm{CCUG} 49529^{\mathrm{T}}\right.$ $=$ KCTC $13178^{\mathrm{T}}$ ), was isolated from human cerebrospinal fluid. The DNA $\mathrm{G}+\mathrm{C}$ content of the type strain is $36.3 \mathrm{~mol} \%$.

\section{Acknowledgements}

We are grateful to Dr Jean. P. Euzéby (Society for Systematic and Veterinary Bacteriology, France) for his advice on nomenclatural queries and to Dr Kämpfer for his valuable advice. This work was supported by grant NMC0301039, a Korea Science and Engineering Foundation (KOSEF) grant (no. M10508040002-07N0804-00216), and by the KRIBB Research Initiative Program funded by the Ministry of Education, Science and Technology, Republic of Korea.

\section{References}

Ahmed, I., Yokota, A., Yamazoe, A. \& Fujiwara, T. (2007). Proposal of Lysinibacillus boronitolerans gen. nov. sp. nov., and transfer of Bacillus fusiformis to Lysinibacillus fusiformis comb. nov. and Bacillus sphaericus to Lysinibacillus sphaericus comb. nov. Int J Syst Evol Microbiol 57, 1117-1125.

Albert, R. A., Archambault, J., Lempa, M., Hurst, B., Richardson, C., Gruenloh, S., Duran, M., Worliczek, H. L., Huber, B. E. \& other authors (2007). Proposal of Viridibacillus gen. nov. and reclassification of Bacillus arvi, Bacillus arenosi and Bacillus neidei as Viridibacillus arvi gen. nov., comb. nov., Viridibacillus arenosi comb. nov. and Viridibacillus neidei comb. nov. Int J Syst Evol Microbiol 57, 2729-2737.

Ash, C., Farrow, J. A. E., Wallbanks, S. \& Collins, M. D. (1991). Phylogenetic heterogeneity of the genus Bacillus revealed by comparative analysis of small-subunit-ribosomal RNA sequences. Lett Appl Microbiol 13, 202-206.

Chang, Y. H., Han, J. I., Chun, J. S., Lee, K. C., Rhee, M. S., Kim, Y. B. \& Bae, K. S. (2002). Comamonas koreensis sp. nov., a non-motile species from wetland in Woopo, Korea. Int J Syst Evol Microbiol 52, 377-381.

Chang, Y. H., Jung, M. Y., Park, I. S. \& Oh, H. M. (2008). Sporolactobacillus vineae sp. nov., a spore-forming lactic acid bacterium isolated from vineyard soil. Int J Syst Evol Microbiol 58, 2316-2320.

Claus, D., Fritze, D. \& Kocur, M. (1992). Genera related to the genus Bacillus - Sporolactobacillus, Sporosarcina, Planococcus, Filibacter and Caryophanon. In The Prokaryotes: a Handbook on the Biology of Bacteria: Ecophysiology, Isolation, Identification, Applications, 2nd edn, vol. 2, pp. 1769-1791. Edited by A. Balows, H. G. Trüper, M. Dworkin, W. Harder \& K. H. Schleifer. New York: Springer.
Coorevits, A., Dinsdale, A. E., Heyrman, J., Schumann, P., Van Landschoot, A., Logan, N. A. \& De Vos, P. (2012). Lysinibacillus macroides sp. nov., nom. rev. Int J Syst Evol Microbiol 62, 11211127.

DSMZ (2001). Catalogue of Strains, 7th edn, p. 617. Braunschweig: DSMZ. http://www.dsmz.de/fileadmin/Bereiche/Microbiology/Dateien/ Key_to_Murein2.pdf.

Ezaki, T., Hashimoto, Y. \& Yabuuchi, E. (1989). Fluorometric deoxyribonucleic acid-deoxyribonucleic acid hybridization in microdilution wells as an alternative to membrane filter hybridization in which radioisotopes are used to determine genetic relatedness among bacterial strains. Int J Syst Bacteriol 39, 224-229.

Farrow, J. A. E., Wallbanks, S. \& Collins, M. D. (1994). Phylogenetic interrelationships of round-spore-forming bacilli containing cell walls based on lysine and the non-spore-forming genera Caryophanon, Exiguobacterium, Kurthia, and Planococcus. Int J Syst Bacteriol 44, 74-82.

Felsenstein, J. (1981). Evolutionary trees from DNA sequences: a maximum likelihood approach. J Mol Evol 17, 368-376.

Felsenstein, J. (1985). Confidence limits on phylogenies: an approach using the bootstrap. Evolution 39, 783-791.

Felsenstein, J. (1993). PHYLIP (phylogeny inference package), version 3.5c, Seattle: Department of Genetics, University of Washington.

Fitch, W. M. (1971). Toward defining the course of evolution: minimum change for a specific tree topology. Syst Zool 20, 406416.

Glazunova, O. O., Raoult, D. \& Roux, V. (2006). Bacillus massiliensis sp. nov., isolated from cerebrospinal fluid. Int J Syst Evol Microbiol 56, 1485-1488.

Gonzalez, J. M. \& Saiz-Jimenez, C. (2002). A fluorimetric method for the estimation of $\mathrm{G}+\mathrm{C}$ mol\% content in microorganisms by thermal denaturation temperature. Environ Microbiol 4, 770-773.

Heyrman, J., Rodríguez-Díaz, M., Devos, J., Felske, A., Logan, N. A. \& De Vos, P. (2005). Bacillus arenosi sp. nov., Bacillus arvi sp. nov. and Bacillus humi sp. nov., isolated from soil. Int J Syst Evol Microbiol 55, 111-117.

Jeon, Y. S., Chung, H., Park, S., Hur, I., Lee, J. H. \& Chun, J. (2005). jPHYDIT: a JAVA-based integrated environment for molecular phylogeny of ribosomal RNA sequences. Bioinformatics 21, 31713173.

Jukes, T. H. \& Cantor, C. R. (1969). Evolution of protein molecules. In Mammalian Protein Metabolism, vol. 3, pp. 21-132. Edited by H. N. Munro. New York: Academic Press.

Kämpfer, P., Blasczyk, K. \& Auling, G. (1994). Characterization of Aeromonas genomic species by using quinone, polyamine, and fatty acid patterns. Can J Microbiol 40, 844-850.

Kämpfer, P., Rosselló-Mora, R., Falsen, E., Busse, H. J. \& Tindall, B. J. (2006). Cohnella thermotolerans gen. nov., sp. nov., and classification of 'Paenibacillus hongkongensis' as Cohnella hongkongensis sp. nov. Int J Syst Evol Microbiol 56, 781-786.

Keddie, R. M. \& Jones, D. (1992). The genus Kurthia. In The Prokaryotes: a Handbook on the Biology of Bacteria: Ecophysiology, Isolation, Identification, Applications, 2nd edn, vol. 2, pp. 1654-1662. Edited by A. Balows, H. G. Trüper, M. Dworkin, W. Harder \& K. H. Schleifer. New York: Springer.

Komagata, K. \& Suzuki, K. (1987). Lipid and cell-wall analysis in bacterial systematics. Methods Microbiol 19, 161-207.

Krishnamurthi, S., Chakrabarti, T. \& Stackebrandt, E. (2009). Re-examination of the taxonomic position of Bacillus silvestris Rheims et al. 1999 and proposal to transfer it to Solibacillus gen. 
nov. as Solibacillus silvestris comb. nov. Int J Syst Evol Microbiol 59, 1054-1058.

Krishnamurthi, S., Ruckmani, A., Pukall, R. \& Chakrabarti, T. (2010). Psychrobacillus gen. nov. and proposal for reclassification of Bacillus insolitus Larkin \& Stokes, 1967, B. psychrotolerans Abd-El Rahman et al., 2002 and B. psychrodurans Abd-El Rahman et al., 2002 as Psychrobacillus insolitus comb. nov., Psychrobacillus psychrotolerans comb. nov. and Psychrobacillus psychrodurans comb. nov. Syst Appl Microbiol 33, 367-373.

La Duc, M. T., Satomi, M. \& Venkateswaran, K. (2004). Bacillus odysseyi sp. nov., a round-spore-forming bacillus isolated from the Mars Odyssey spacecraft. Int J Syst Evol Microbiol 54, 195-201.

Lee, C. S., Jung, Y.-T., Park, S., Oh, T.-K. \& Yoon, J.-H. (2010). Lysinibacillus xylanilyticus sp. nov., a xylan-degrading bacterium isolated from forest humus. Int J Syst Evol Microbiol 60, 281-286.

MacKenzie, S. L. (1987). Gas chromatographic analysis of amino acids as the $N$-heptafluorobutyryl isobutyl esters. J Assoc Off Anal Chem 70, 151-160.

Miwa, H., Ahmed, I., Yokota, A. \& Fujiwara, T. (2009). Lysinibacillus parviboronicapiens sp. nov., a low-boron-containing bacterium isolated from soil. Int J Syst Evol Microbiol 59, 1427-1432.

Nakamura, L. K., Shida, O., Takagi, H. \& Komagata, K. (2002). Bacillus pycnus sp. nov. and Bacillus neidei sp. nov., round-spored bacteria from soil. Int J Syst Evol Microbiol 52, 501-505.

Saitou, N. \& Nei, M. (1987). The neighbor-joining method: a new method for reconstructing phylogenetic trees. Mol Biol Evol 4, 406-425.

Schleifer, K. H. (1985). Analysis of the chemical composition and primary structure of murein. Methods Microbiol 18, 123-156.

Schleifer, K. H. \& Kandler, O. (1972). Peptidoglycan types of bacterial cell walls and their taxonomic implications. Bacteriol Rev 36, 407-477.

Shaw, S. \& Keddie, R. M. (1983). A numerical taxonomic study of the genus Kurthia with a revised description of Kurthia zopfii and a description of Kurthia gibsonii sp. nov. Syst Appl Microbiol 4, 253-276.
Smibert, R. M. \& Krieg, N. R. (1994). Phenotypic characterization. In Methods for General and Molecular Bacteriology, pp. 607-654. Edited by P. Gerhardt, R. G. E. Murray, W. A. Wood \& N. R. Krieg. Washington, DC: American Society for Microbiology.

Tindall, B. J. (1990). A comparative study of the lipid composition of Halobacterium saccharovorum from various sources. Syst Appl Microbiol 13, 128-130.

Tindall, B. J., Rosselló-Móra, R., Busse, H.-J., Ludwig, W. \& Kämpfer, P. (2010). Notes on the characterization of prokaryote strains for taxonomic purposes. Int J Syst Evol Microbiol 60, 249-266.

Vaishampayan, P., Miyashita, M., Ohnishi, A., Satomi, M., Rooney, A., La Duc, M. T. \& Venkateswaran, K. (2009). Description of Rummeliibacillus stabekisii gen. nov., sp. nov. and reclassification of Bacillus pycnus Nakamura et al. 2002 as Rummeliibacillus pycnus comb. nov. Int J Syst Evol Microbiol 59, 1094-1099.

Wayne, L. G., Brenner, D. J., Colwell, R. R., Grimont, P. A. D., Kandler, O., Krichevsky, M. I., Moore, L. H., Moore, W. E. C., Murray, R. G. E. \& other authors (1987). International Committee on Systematic Bacteriology. Report of the ad hoc committee on reconciliation of approaches to bacterial systematics. Int J Syst Bacteriol 37, 463-464.

Woese, C. R., Magrum, L. J., Gupta, R., Siegel, R. B., Stahl, D. A., Kop, J., Crawford, N., Brosius, J., Gutell, R. \& other authors (1980). Secondary structure model for bacterial $16 \mathrm{~S}$ ribosomal RNA: phylogenetic, enzymatic and chemical evidence. Nucleic Acids Res 8, 2275-2293.

Yoon, J. H., Lee, K. C., Weiss, N., Kho, Y. H., Kang, K. H. \& Park, Y. H. (2001). Sporosarcina aquimarina sp. nov., a bacterium isolated from seawater in Korea, and transfer of Bacillus globisporus (Larkin and Stokes 1967), Bacillus psychrophilus (Nakamura 1984) and Bacillus pasteurii (Chester 1898) to the genus Sporosarcina as Sporosarcina globispora comb. nov., Sporosarcina psychrophila comb. nov. and Sporosarcina pasteurii comb. nov., and emended description of the genus Sporosarcina. Int J Syst Evol Microbiol 51, 1079-1086. 